\title{
Author Correction: PGBD5 promotes site-specific oncogenic mutations in human tumors
}

Anton G. Henssen, Richard Koche, Jiali Zhuang, Eileen Jiang, Casie Reed, Amy Eisenberg, Eric Still, lan C. MacArthur, Elias Rodríguez-Fos, Santiago Gonzalez, Montserrat Puiggròs, Andrew N. Blackford, Christopher E. Mason, Elisa de Stanchina, Mithat Gönen, Anne-Katrin Emde, Minita Shah, Kanika Arora, Catherine Reeves, Nicholas D. Socci, Elizabeth Perlman, Cristina R. Antonescu, Charles W. M. Roberts, Hanno Steen, Elizabeth Mullen, Stephen P. Jackson (10, David Torrents, Zhiping Weng, Scott A. Armstrong and Alex Kentsis (i)

Correction to: Nature Genetics https://doi.org/10.1038/ng.3866, published online 15 May 2017.

In the version of this article initially published, in the Results, the statement ' 580 (52\%) of 1,121 somatic genomic rearrangements detected in rhabdoid tumors contained PSS sequences near their rearrangement breakpoints' should have read '369 (34\%) of 1,087 somatic genomic rearrangements detected in rhabdoid tumors contained PSS sequences near their rearrangement breakpoints'. The conclusions are not affected.

Published online: 11 September 2020

https://doi.org/10.1038/s41588-020-00711-z

(c) The Author(s), under exclusive licence to Springer Nature America, Inc. 2020

\section{Author Correction: WNT signaling and AHCTF1 promote oncogenic MYC expression through super-enhancer-mediated gene gating}

Barbara A. Scholz, Noriyuki Sumida (D), Carolina Diettrich Mallet de Lima, llyas Chachoua (D), Mirco Martino(D),

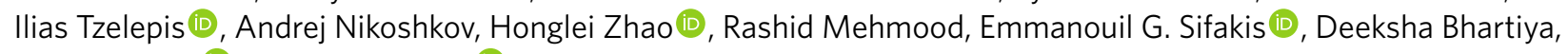
Anita Göndör (1D and Rolf Ohlsson (1)

Correction to: Nature Genetics https://doi.org/10.1038/s41588-019-0535-3, published online 29 November 2019.

In the version of this article initially published, an affiliation indicating that authors Anita Göndör and Rolf Ohlsson jointly supervised the work was missing. The Author contributions have additionally been updated to state that these authors contributed equally as joint senior authors. The errors have been corrected in the HTML and PDF versions of the article.

Published online: 18 September 2020

https://oi.org/10.1038/s41588-020-00715-9

๑ The Author(s), under exclusive licence to Springer Nature America, Inc. 2020 